Does text familiarity predict schema automation to reduce Working Memory Capacity constraints for enhanced reading comprehension? A study from Ghana

Ntim, Stephen

Catholic University of Ghana, Ghana, West Africa (stephen.ntim@cug.edu.gh)

Received: 10 August 2017 Available Online: 27 October 2017
Revised: 30 September 2017 DOI: $10.5861 /$ ijrsp.2017.1892

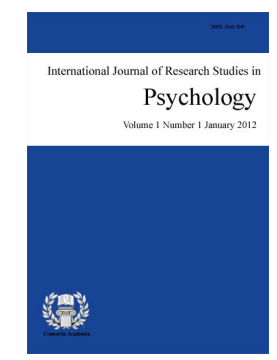

ISSN: 2243-7681 Online ISSN: 2243-769X

OPEN ACCESS

\title{
Abstract
}

This report tested four measures to assess how texts familiarity significantly influences reading efficiency of students having prior knowledge of text from those with no prior knowledge. In all measures, results suggested significant differences in favor of experimental groups exposed to familiar texts than the controlled groups without prior text knowledge. Data were interpreted to mean that previous knowledge was a critical predicting factor for schema automation reducing working memory constraints for enhanced reading comprehension. Readers' privy to information were hypothesized to have used text schemata to manage and process text in parallel as one element, allowing working memory constraints to be circumvented, leaving space to focus on other mental processes, which enabled readers with background knowledge to distinguish between relevant and irrelevant information. Findings were interpreted as the plausible interrelated link between text familiarity, schema automation and Working Memory reduction. Implications for classroom practice are suggested.

Keywords: previous knowledge; schemata; working memory; comprehension 


\section{Does text familiarity predict schema automation to reduce Working Memory Capacity constraints for enhanced reading comprehension? A study from Ghana}

\section{Introduction}

Many research studies suggest that background or contextual knowledge support reading comprehension and recall (Summers, Horton, \& Diehl, 1985; Adams, Bell, \& Perfetti, 1995; Rawson \& Kintsch, 2002). Additionally, there is ample evidence supporting the notion that prior knowledge or previous knowledge that one has, is a predicting factor in reducing the time required for processing text, especially when measured in terms of reaction time or speed (Miller \& Stine-Morrow, 1998; Wiley \& Rayner, 2000; Kaakinen, Hyönä, \& Keenan, 2003). Given the fact that, prior knowledge of text reduces Working Memory constraints, the argument could equally be made, that one who has previous knowledge of information typically will comprehend a text better, than one without any background information. This implies that a person with knowledge about a given subject, finds it easier to comprehend and recall texts (Ericsson \& Kintsch, 1995; Vicente \& Wang, 1998; Shapiro, 2004) more accurately.

This is because reading is essentially cognitive. It involves varied mental processes. For example, a reader would have to extract meaning from orthographic symbols, choose text segments and input them into working memory in cycle through such cognitive processes as follows: a) decoding letters and identifying words; b) accessing the meaning of these words, c) forming syntactic units by assigning thematic roles to words (Nation \& Snowling, 1988). Each of these processes constitutes propositions or ideas that need to be organized within sentences, and at the same time, be linked across sentences, so that a text base representation could be formed. While all these lower mental processes are going in the mind of the reader, simultaneously, he/she must also be able to make inferences not stated verbatim in the text. This higher representation is generally referred to as ‘situation model' or 'mental model' respectively by Van Dijk and Kintsch (1983) and Johnson-Laird (1983).

It is in this respect that reading and text comprehension are both implicated by Working Memory Capacity (WMC) constrains (Miller, 1956). Therefore, if it is the Working Memory that both stores and manipulates information, the implication is that each of the above reading operations is likely to implicate the Working Memory (WM) in terms of demands (Baddeley \& Hitch, 1974; Daneman \& Carpenter, 1980; Engle, 2001).

Reports consistently show that Ghanaian children have poor reading culture (Ghartey, 2010). Few studies in Ghana and in many parts of Africa have focused on the link between text familiarity, schema automation activation and their plausible implication on Working Memory constraints and reading. Additionally, few scientific studies in Ghana, have been conducted to examine the extent to which prior knowledge predicts efficient reading. In this paper, previous knowledge is hypothesized to enhance both lower and higher cognitive processes in reading, such as, word de-codification, accessing meaning of words, assigning thematic roles to words, making inferences, etc. When one is exposed to previous text, one is able to align the previous knowledge with the new texts. In this sense, the reader is able to activate schemata, which would allow processing instantiation, and by so doing, reducing Working Memory constraints to improve reading comprehension.

Consequently, this paper sought to find answers to these questions:

$>$ Does contextual knowledge reduce constraints on Working Memory?

$>\quad$ If contextual knowledge implicates working memory load, does this lead to differences in reading efficiency between those with prior knowledge, and those without prior knowledge?

$>\quad$ Does prior knowledge reduce working memory constraints during reading? 


\section{Literature}

\subsection{Reading comprehension}

Reading comprehension is nothing more, nothing less than making meaning from a text. This meaning-making implies that one has understanding. It is on the basis of this understanding, that one can interpret the text, and make inferences beyond what is literally mentioned. This skill is contingent on interrelated factors involving the reader, the given text and the situation. Meaning formed in the mind of reader is linked to his/her previous/contextual knowledge (Griffin, Malone, \& Kameenui, 1995; Cain \& Oakhill, 1999). The assumption is that, reader's existing knowledge critically determines, how he/she acquires new information of text, which is also linked up with how readily readers generate theses, schemata and other mental modules (Vipond, 1980).The goal of comprehension is for readers to have global understanding of texts. This is accomplished, when they develop skills for mental models or semantic (meaning) representation during reading. Two types of skills are involved: a) one based on text, and b) one based on the situation. The former has to do with readers' mental representation of text, and the latter, readers' perception of what text information is about. Good readers using these processes make inferences to arrive at this global understanding (Van Dijk \& Kintsch, 1983; Kintsch, 1998a; Kintsch, 1988b), which permits knowledge flexibility, allowing for the integration of visual and verbal representations (Pearson \& Johnson, 1978; Snow, 2002; Stull \& Mayer, 2007).

\subsection{Comprehension as cognitive process}

Comprehension as explained above, implies that reading for comprehension, is implicated by a number of cognitive processes and skills. Consequently, failure in any of these, is likely to precipitate comprehension challenges (Cain \& Oakhill, 2007). For example, it has been postulated, that the skill to derive meaning from text is contingent upon Working Memory Capacity (WMC) load. Therefore, when words and phrases are so identified, the psychological postulate is that some space is created in the WMC, to bring some meaning to unfamiliar words encountered in the text, faster than the reader with no reduction in the cognitive load (Daneman \& Green, 1986; Pressley 1998; Manset-Williamson \&Nelson, 2005;). What this means is that, skilled readers, unlike unskilled readers, are more able to efficiently gain meanings from unfamiliar words, and vocabularies, because they have a better and efficient ways of making use of clues through previous/background knowledge (Stanovich, 1986; Kuhn \& Stahl, 1998; Ewers \& Brownson, 1999; Goerss, Beck, \& Mckeown, 1999).

\subsection{Schemata and comprehension}

The use of effective clues in reading is related to schemata. A schema is an associated knowledge representing categories of situations, events, as well as things (Anderson, Pichert, \& Shirey, 1983). Reed (1993) sees schema in generic terms, constituting a concept, which can be instantiated, having certain characteristics, such as abstraction, instantiation, prediction, organisation, etc. (Detterman, 1993). Through schemas, one can make inferences or induction from every day experience (Anderson, Stevens, Shifrin, \& Osborn, 1978; Anderson \& Pearson, 1984; Anderson, 1994). Let us take for example, the schema of going to a restaurant. One can infer things a person who goes to a restaurant will do: a) call for menu; b) check through menu, c) make an order, d) eat, e) pay bill, and f) leave. These are instances one would expect to take place typically in a restaurant. Consequently, if one has this schema in one's Long Term Memory (LTM), one can make some plausible inferences from what happens in a restaurant.

Similarly, in reading, the understanding (schema) that a reader brings to the text, becomes heightened, when a given schema helps the reader to make some interpretations and inferences from the text information, by recalling such information from the LTM. Thus, effective schemas are able to provide some standard for editing out relevant from what is irrelevant. This process enhances readers' inferential reconstruction, making comprehension become easier (Anderson, Pichert, \& Shirey, 1983). Consequently, if text passage effectively 
Ntim, S.

activates readers' schemata or previous knowledge, they comprehend what they read, and this constitutes a critical mental predicting factor to understand text better (Freebody \& Anderson, 1983; Anderson, Wang, \& Gaffney, 2006).

\subsection{Context and reading comprehension}

Schema-based processes described above are linked to context. 'Context', as applied to reading comprehension, is used variedly, even though, it connotes the same concept. Context in reading comprehension, has to do with the way reading materials are presented, and characteristics the reader brings to the text he/she is reading. For example, discourse considered proximal to a targeted word or passage, as well as circumstances surrounding a situation, are considered contextual, because, they facilitate to make meaning in reading texts. Word recognition and reading comprehension, could hardly be accomplished effectively, without making use of related contexts of both word and sentences, regarding their implied meaning (Bruning, Schraw, Norby, \& Ronning, 2011). Context helps in decoding, which influences vocabulary directly (Nagy, Herman, \& Anderson, 1985; Nagy, Anderson, \& Herman, 1987). Successful decoding has two fundamental events: a) retrieval of meanings of familiar words, which strengthens form-meaning connections, and b) decoding also establishes context-dependent links, between familiar words and meaning making (Nation \& Snowling, 1988). Contextual information therefore, is critical, in helping to draw the necessary relations from words, sentences, making meaning of new vocabularies, as well, as making inferences (Schwanenflugel \& Shoben, 1983). Comprehending of text is also facilitated, when readers are able to combine contextual information to the text they are reading (Brandsford \& Johnson, 1972).

\subsection{Text signaling and reading comprehension}

Signaling with respect to comprehension is a kind of text cueing (Loman \& Mayer, 1983). Text signaling has multiple aims, such as: a) to guide learners effective cognitive processing; b) to assist text readers in the allocation of mental resources to important parts of contents; c) to help readers to figure out relevant and significant information; d) to guide learners attention to important organizational and content features. Lorch and Chen (1986), Glover, Dinnal, Halpain, Mckee, Corkill, and Wise (1988) findings, suggest the importance of signaling in the recall of text. The underlying psychological assumption is that, if some parts of text are highlighted, either in the form of title and heading, logical connections, summary statements, typographical cues, etc., these draw readers' attention. By fulfilling all these mental functions, readers' cognitive load becomes optimized, and comprehension is improved. Empirical studies corroborate that more selective attention is paid to highlighted parts of text, when signaling is offered (Britton, Glynn, Meyer \& Penland, 1982; Lorch \& Lorch, 1985; Lorch, Lorch, \& Inman, 1993).

\subsection{Cognitive load theory (CLT) and schema automation}

The theoretical framework of cognitive load is underscored by the following fundamental assumptions consistent with the information processing model: a) limited Working Memory (WM) in terms of capacity and duration, and b) unlimited Long Term Memory (LTM). WM can hold limited information (Miller, 1956). Thus, when the WM exceeds its capacity limits, mental/cognitive processing could be undermined, even though, such constraints may apply only to new information (Bruning, Schraw, \& Norby, 2011). It is on this basis that CLT focuses on how to reduce overloaded WM, when individual learns new materials (van Merriënboer \& Sweller, 2005). While making a case for limited WM, CLT, not only assume unlimited capacity for LTM, but also makes the case, that in the LTM, knowledge is structured into complicated representations, referred to as schemas, which operate like a central executive structure, which can activate, summaries and instantiate information. This contributes to reducing WM load. In short, CLT makes the case that schemata mediate the reduction of WM load. Consequently, when readers make use of requisite schemata, complex information could be processed in parallel, rather than serially. This process, called, schema automation, assists readers and learners to circumvent the WM restrictions, allowing cognitive process to occur without too much constraints (Sweller, van Merriënboer, \& Paas, 
1998).

\subsection{Present Study}

The literature reviewed above, could be summed up as highlighting the following important points: a) that reading comprehension is implicated by cognitive processes; b) consequently, failure in any of the processes could induce comprehension challenges; c) comprehension is facilitated, when for example, through schema and schema-based processes, signaling and other context effects, cognitive processes, such as inferential elaboration, attention allocation, text reconstruction, summarizing, editing etc., are enhanced.; d) through such psychological processes, it is assumed cognitive load is reduced, and therefore skilled comprehension would be enhanced.

With this as backdrop, the underlying hypothesis that this paper sought to test was this: if contextual knowledge implicates working memory load, through schema automation, this should lead to differences in reading efficiency between those with prior knowledge, and those without prior knowledge (cf. Summers, Horton \& Diehl, 1985; Adams, Bell \& Perfetti, 1995; Rawson \& Kintsch, 2002). In other words, the prediction in this study was that experimental group exposed to analogous texts was hypothesised to: i) perform better in text comprehension than the control, through the process of schema automation, due to prior exposure to analogous text ; ii) precisely because this previous exposure induced schema automation, more space was likely to be created in the Working Memory, to make the experimental group to attend to what was relevant, from what was irrelevant, during text processing.

\section{Methodology}

\subsection{Sample}

This study used an estimated purposive sampling size of two hundred and forty (240) Junior High School pupils, randomly, selected from four (4) community basic schools in two selected regions of Ghana. One hundred and twenty (120) pupils, between the ages of 11-14, from Junior High School Forms 1-3, were selected from each of the two regions, making a total of two hundred and forty (240). Two basic schools were randomly chosen from the region of Ashanti: one from Kumasi, and the other from the southern part of Offinso. In the Bono and Ahafo area, one school was selected from the Sunyani West district, and one from Bekyem. About fifty percent of the estimated sample was male and the remaining was females. The demographic data of parental background of respondents were from the following categories of employment: a) civil service, b) working class, c) self-employed and d) farming backgrounds. The children randomly sampled from Sunyani, Bekyem and the Offinso South were all Ghanaians. In Kumasi, few of the children had some foreign parentage, such as Lebanese, Nigerians, and some Togolese. All these children and their parents were not native speakers of English.

\subsection{Materials and Design}

Respondents were randomly grouped into: a) experimental group and b) a control group. The former was given series of analogous passages to read two days before the experiment and had some interventions. For example, in the understanding of the problem in the texts, the experimental group was guided before the test to ask such questions as: a) Have I carefully read and analyzed the problem at hand? b) Can I restate or translate the problem? c) Am I capable to reconceptualise the problem in visual or graphic form? d) Can I make inference of important points, not explicitly stated in the information? In the identification of the relevant data in the texts, the experimental group was guided to formulate and asks themselves the following: What is the problem asking? What information is necessary to answer that question? What is the answer to that question? As regards the monitoring of cognitive processes, students were guided to ask themselves the subsequent questions to check their comprehension between their base knowledge and the target knowledge as presented in each text: What is the present state of this problem in this text? What is the goal? What are the resources needed to solve this problem? What are the operations that will be needed to use these resources? Are there any constraints and if 
Ntim, S.

there are, how do we overcome them in this particular instance? Based on these constraints and operations, what is the better solution plan? What will be the outcome in using this solution plan? The control had no previous knowledge of the text nor any of the intervention listed above.

\subsection{Procedure}

Experiment - The experiment was conducted in each school simultaneously with the help of research assistants. In each school, the two groups were given the same sets of texts, which were different from, but analogous, to what was used at the prior intervention for the experimental group: In each text, there was: a) a base text with a problem and the solution is given in this text. In text (b) which is the analogous problem, the solution is not given, but have similar pattern as the problem in the base text. They were required to infer the solution to the analogous text in (b) from the base text in (a). For example in text (a) there is a story titled 'Red Adair'. This was an Arabian oil well exploding and catching fire. The fire could be extinguished only with a large quantity of retardant. Enough retardant was available. The constraint was lack of hose that was large enough to contain all the retardant to put out the fire quickly. This constraint was circumvented as follows: Red Adair had men circled all around the fire with the limited hoses. When all was ready, the hoses were opened simultaneously from all directions. The combined retardant from the small hoses from all directions extinguished the fire.

In text (b), there was an analogous story, but with different context, titled 'Fragile-Glaser/Laser Version'. The story in text (b) was about a Physics laboratory in a University. Emily was the research assistant in this laboratory. Coming to the lab one morning, she discovered the light bulb did not function, having failed to put it off the previous day. The bulb had become overheated breaking the filament into two. Opening it was a challenge, because glass surrounding it was sealed, hence there was no possibility of opening it. However, the lab had enough equipment to open it, but challenge was that in doing so, the high-intensity laser beam could also break the glass. How could Emily overcome this challenge, without breaking the glass, but at the same time fusing the filament?

Thus Test 1 and Test 2 had a base and analogous text passages. In all the passages, students were tested along the following four measures: a) recall question (that is fact related question), b) inference-making question, c) pattern recognition (schemas) and d) summary question. Each measure had five (5) sub-questions, each sub-question was marked over 5, making 25 point score for each question, making a total of 100 . Each set of texts, shared similar schema: 'using simultaneous force' to either bring a fire under control, or solving a laboratory problem. Text signaling used to control comprehension in the summary questions, included logical connections, as 'in summary', 'therefore', 'in fact'. Scores were computed into mean and standard deviations.

\section{Results}

Table 1

Descriptive statistics for Form One experimental and control groups

\begin{tabular}{llcccc}
\hline \multicolumn{2}{c}{ FORM ONE } & $n$ & Mean & SD & Std. error $M$ \\
\hline Score on recall questions & Experimental & 40 & 16.60 & 3.56 & 0.56 \\
& Control & 40 & 14.18 & 2.84 & 0.45 \\
Scores obtained on inference & Experimental & 40 & 16.15 & 4.00 & 0.63 \\
making questions & Control & 40 & 13.85 & 2.96 & 0.47 \\
Scores obtained on pattern & Experimental & 40 & 15.68 & 3.60 & 0.57 \\
recognition questions & Control & 40 & 12.60 & 2.70 & 0.43 \\
Score obtained on summary & Experimental & 40 & 16.35 & 3.05 & 0.48 \\
questions & Control & 40 & 12.85 & 2.77 & 0.44 \\
\hline
\end{tabular}


In all the four tests, experimental group performed better than the control group. However, their standard deviations indicate that, in all cases, scores obtained by control group were closely related to one another than the experimental group. Experimental group had higher standard deviation than the control group suggesting that their scores were more varied.

Using the independent samples t-test at an alpha level of 0.05 , a follow-up test to confirm whether the mean differences were significant was conducted. Since the Levene's test for equality of variance were not significant in all the four cases, the t-values corresponding to equal variance assumed was taken in all the cases. The results showed that the experimental group outperformed the control group on recall questions. The t-test at alpha $=0.01$ showed a statistically significant difference between the performance of the two groups [t=2.92, $p=0.01]$.

Table 2

Descriptive statistics for Form Two experimental and control groups

\begin{tabular}{lllllc}
\hline \multicolumn{2}{c}{ FORM ONE } & $n$ & Mean & SD & Std. error $M$ \\
\hline Score on recall questions & Experimental & 40 & 17.90 & 3.38 & 0.53 \\
& Control & 40 & 15.50 & 3.40 & 0.54 \\
Scores obtained on inference & Experimental & 40 & 17.28 & 3.11 & 0.49 \\
making questions & Control & 40 & 14.45 & 3.23 & 0.51 \\
Scores obtained on pattern & Experimental & 40 & 16.68 & 3.06 & 0.48 \\
recognition questions & Control & 40 & 13.40 & 2.83 & 0.45 \\
Score obtained on summary & Experimental & 40 & 17.95 & 3.11 & 0.49 \\
questions & Control & 40 & 14.10 & 2.99 & 0.47 \\
\hline
\end{tabular}

Results of From Two are presented in the above Table 2. On the last two variables, the scores of the experimental group were more dispersed than the control group. Independent samples t-tests were again run to find out whether the experimental group actually performed better than the control group as their means suggested. At 5\% significant level, result of the independent t-test showed that on the recall questions, the mean score of the experimental group was significantly higher than that of the control group [t=3.17, $p=0.02]$. There was also a statistically significant difference in the performance of the experimental and the control group on the inference making questions in favor of the experimental group $[t=3.99 \mathrm{p}=0.00]$. The experimental group had significantly higher mean scores on the last two variables, pattern recognition and summary questions than the control group $[\mathrm{t}=4.97, p=0.00]$ and $[\mathrm{t}=5.64, p=0.00]$ respectively.

Table 3

Descriptive statistics for Form Three experimental and control groups

\begin{tabular}{llcccc}
\hline \multicolumn{2}{c}{ FORM ONE } & $n$ & Mean & SD & Std. error $M$ \\
\hline Score on recall questions & Experimental & 40 & 19.18 & 3.49 & 0.55 \\
& Control & 40 & 15.50 & 3.40 & 0.53 \\
Scores obtained on inference & Experimental & 40 & 18.38 & 3.23 & 0.51 \\
making questions & Control & 40 & 14.75 & 3.26 & 0.51 \\
Scores obtained on pattern & Experimental & 40 & 17.95 & 3.11 & 0.49 \\
recognition questions & Control & 40 & 14.10 & 2.99 & 0.47 \\
Score obtained on summary & Experimental & 40 & 17.10 & 2.96 & 0.47 \\
questions & Control & 40 & 13.32 & 2.38 & 0.38 \\
\hline
\end{tabular}

The results obtained for the experimental and control groups from Form Three on the variables are presented in Table 3. The t-test showed that their performance was significantly higher than that of the control group which was 13.32 and 2.38 respectively. [t=6.29, $p=0.00]$. 


\section{ANOVA TESTS}

\section{Table 4}

One-way analysis of variance test to compare the performance of the three control groups

\begin{tabular}{|c|c|c|c|c|c|c|}
\hline & & $\begin{array}{l}\text { Sum of } \\
\text { Squares }\end{array}$ & $\mathrm{df}$ & $\begin{array}{l}\text { Mean } \\
\text { Square }\end{array}$ & $\mathrm{F}$ & Sig. \\
\hline \multirow[t]{3}{*}{ Score on recall questions } & Between Groups & 46.82 & 2 & 23.41 & 2.26 & 0.11 \\
\hline & Within Groups & 1213.78 & 117 & 10.37 & & \\
\hline & Total & 1260.59 & 119 & & & \\
\hline \multirow{3}{*}{$\begin{array}{l}\text { Scores obtained on } \\
\text { inference making } \\
\text { questions }\end{array}$} & Between Groups & 16.80 & 2 & 8.40 & 0.84 & 0.43 \\
\hline & Within Groups & 1160.50 & 117 & 9.92 & & \\
\hline & Total & 1177.30 & 119 & & & \\
\hline \multirow{3}{*}{$\begin{array}{l}\text { Scores obtained on pattern } \\
\text { recognition questions }\end{array}$} & Between Groups & 45.07 & 2 & 22.53 & 2.79 & 0.07 \\
\hline & Within Groups & 944.80 & 117 & 8.08 & & \\
\hline & Total & 989.87 & 119 & & & \\
\hline \multirow{3}{*}{$\begin{array}{l}\text { Score obtained on } \\
\text { summary questions }\end{array}$} & Between Groups & 31.85 & 2 & 15.93 & 2.14 & 0.12 \\
\hline & Within Groups & 869.48 & 117 & 7.43 & & \\
\hline & Total & 901.33 & 119 & & & \\
\hline
\end{tabular}

One-way analysis of variance was conducted at 5\% significant level to compare the performance of the three different control groups on the four variables. The result indicated that there were no significant differences between the performances of the groups on all the variables. The mean scores of the three groups on all the four variables were similar. For example, on the recall questions, it showed $\mathrm{F}=2.7$ and $p=0.11$, which was not significant at 0.05 alpha level.

Table 5

One-way analysis of variance test to compare the performances of the three experimental groups

\begin{tabular}{llccccc}
\hline & & $\begin{array}{c}\text { Sum of } \\
\text { Squares }\end{array}$ & df & Mean Square & F & Sig. \\
\hline Score on recall questions & Between Groups & 132.62 & 2 & 66.31 & 5.48 & 0.01 \\
& Within Groups & 1414.98 & 117 & 12.09 & & \\
& Total & 1547.59 & 119 & & & \\
Scores obtained on inference & Between Groups & 99.02 & 2 & 49.51 & 4.11 & 0.02 \\
making questions & Within Groups & 1410.45 & 117 & 12.06 & & \\
& Total & 1509.47 & 119 & & & 0.01 \\
Scores obtained on pattern & Between Groups & 104.02 & 2 & 52.01 & 4.89 & \\
recognition questions & Within Groups & 1245.45 & 117 & 10.65 & & \\
& Total & 1349.47 & 119 & & & \\
Score obtained on summary & Between Groups & 51.27 & 2 & 25.63 & 2.78 \\
questions & Within Groups & 1080.60 & 117 & 9.24 & & \\
& Total & 1131.867 & 119 & & & \\
\hline
\end{tabular}

Again analysis of variance test was conducted to compare the three experimental groups on the four variables. The result of the Anova test at 5\% significant level as found in Table 5 shows that the mean scores of the three groups differ on three of the variables, but similar on one of the variables. The result of the test revealed that the mean scores of the groups on recall questions were significantly different $[\mathrm{F}=5.48, p<0.01]$. The groups also differed significantly in performance on the inference making questions $[\mathrm{F}=4.11, p<0.01]$. The mean scores of the groups on pattern recognition questions were also significantly different $[\mathrm{F}=4.89, p<0.01]$. However, there was no difference in performances of the three groups on summary questions $[\mathrm{F}=2.78, p>0.01$. 
Text familiarity predict schema automation to reduce Working Memory Capacity

A follow up test was conducted to find out the specific groups that performed differently on the three variables; recall, inference making and pattern recognition. To know which of the post hoc tests to use, test of homogeneity of variances was conducted and the results as shown in Table 6 revealed that the variances of the groups on the three variables were not significantly different.

Table 6

Test of homogeneity of variances

\begin{tabular}{lcccc}
\hline & Levene Statistic & df1 & df2 & Sig. \\
\hline Score on recall questions & 0.04 & 2 & 117 & 0.96 \\
Scores obtained on inference making questions & 1.13 & 2 & 117 & 0.33 \\
Scores obtained on pattern recognition questions & 0.52 & 2 & 117 & 0.59 \\
\hline
\end{tabular}

The variances of the groups were assumed to be equal, hence, Bonferroni post hoc test was conducted to compare the groups on the three variables. The result of the post hoc test as seen in Table 7 reveal that on all the three variables (recall, inference making and pattern recognition) there were no significant differences in performance between the form one and form two experimental groups, and also no significant differences were observed between the form two and the form three experimental groups.

Table 7

Post Hoc test to compare the three experimental groups

\begin{tabular}{|c|c|c|c|c|c|}
\hline Dependent Variable & $\begin{array}{l}\text { (I) experimental groups } \\
\text { from the various forms }\end{array}$ & $\begin{array}{l}(\mathrm{J}) \text { experimental } \\
\text { groups from the } \\
\text { various forms }\end{array}$ & $\begin{array}{c}\text { Mean } \\
\text { Difference } \\
(\mathrm{I}-\mathrm{J})\end{array}$ & Std. Error & Sig. \\
\hline \multirow{4}{*}{$\begin{array}{l}\text { Score on recall } \\
\text { questions }\end{array}$} & \multirow[t]{2}{*}{ Form 1 experimental } & Form 2 experimental & -1.30 & 0.78 & 0.29 \\
\hline & & Form 3 experimental & $-2.58^{*}$ & 0.78 & 0.00 \\
\hline & \multirow[t]{2}{*}{ Form 3 experimental } & Form 1 experimental & $2.58^{*}$ & 0.78 & 0.00 \\
\hline & & Form 2 experimental & 1.28 & 0.78 & 0.31 \\
\hline \multirow{4}{*}{$\begin{array}{l}\text { Scores obtained on } \\
\text { inference making } \\
\text { questions }\end{array}$} & \multirow[t]{2}{*}{ Form 1 experimental } & Form 2 experimental & -1.13 & 0.78 & 0.45 \\
\hline & & Form 3 experimental & $-2.23^{*}$ & 0.78 & 0.02 \\
\hline & \multirow[t]{2}{*}{ Form 3 experimental } & Form 1 experimental & $2.23^{*}$ & 0.78 & 0.02 \\
\hline & & Form 2 experimental & 1.10 & 0.78 & 0.48 \\
\hline \multirow{4}{*}{$\begin{array}{l}\text { Scores obtained on } \\
\text { pattern recognition } \\
\text { questions }\end{array}$} & \multirow[t]{2}{*}{ Form 1 experimental } & Form 2 experimental & -1.00 & 0.73 & 0.52 \\
\hline & & Form 3 experimental & $-2.28^{*}$ & 0.73 & 0.01 \\
\hline & \multirow[t]{2}{*}{ Form 3 experimental } & Form 1 experimental & $2.28^{*}$ & 0.73 & 0.01 \\
\hline & & Form 2 experimental & 1.28 & 0.73 & 0.24 \\
\hline
\end{tabular}

However, significant differences were observed between the form three and the form one experimental groups. On the recall questions, the form three group performed significantly higher than the form one group $[\mathrm{MD}=2.58, p<0.01]$. On inference making questions the form one group performed significantly lower than the form three group $[\mathrm{MD}=-2.23, p<0.01]$ and on the pattern recognition questions, the form three experimental group again performed significantly better than the form one experimental group [MD=2.28, $p<0.01]$.

\section{Discussion}

The results above are suggestive of two things: Firstly, the consistent better performance of the experimental groups exposed to background information across the various measures as opposed to the control groups corroborates the fact that familiarity with a topic makes it easier to understand and remember texts. This confirms empirical research findings that suggest a link between contextual knowledge and reading comprehension (Moravcik \& Kintsch, 1993; Adams, Bell, \& Perfetti, 1995; Rawson \& Kintsch, 2002). Secondly, contextual or previous knowledge of a topic appears to be a predicting factor reducing time needed for text 
processing, especially when reading is measured by reading speed or reaction time (Miller \& Stine-Morrow, 1998; Wiley \& Rayner, 2000; Kaakinem, Hyona, \& Keenam, 2003) and the findings seem to strengthen this position. Reading is a blend of varied cognitive processes, such as decoding letters to identify words, deriving meaning of the words as well as combining syntactic units by giving thematic roles to words. These are lower order processes. For enhanced comprehension, reader would also have to be able move above this lower order to make inferences (Van Dijk \& Kintsch, 1983; Johnson-Laird 1983).

As indicated above, the consistent better scores of those exposed to analogous previous knowledge, relative to those who lacked prior knowledge, suggests that Working Memory constraints may have been circumvented by the former groups across the three categories of students. This was taken as plausible influence of their exposure to previous analogous contextual knowledge. As a result of this, the experimental groups spent less time decoding letters, identifying words, and combining syntactic units etc. These lower order processes became automatic through the use of text structure schemata, which were stored already in their Long Term memory. Hence, the processing of information operated like central executive, activating, summarizing and instantiating information. In so doing, Working Memory load was reduced, compensating for better enhanced reading than the control groups, and thus corroborating the findings of Sweller, van Merriënboer, and Paas (1998).

In all the measures, experimental groups who were exposed to background information before the test consistently outperformed the control group. For example as indicated above in Table 3 and the t-test results obtained for the senior students in Form Three, the experimental performed significantly better compared to the control on all four variables at 5\% significant level. On the recall questions, the control group had a mean score of 15.50 and a standard deviation of 3.40 which was significantly lower than the mean score of the experimental group $[\mathrm{M}=19.18, \mathrm{SD}=3.49, \mathrm{t}=4.77, p=0.00]$. Again the experimental group had a statistically significant higher mean $[\mathrm{M}=18.38, \mathrm{SD}=3.23]$ on the inference making questions than the control group $[\mathrm{M}=14.75, \mathrm{SD}=3.26]$, the independent samples $\mathrm{t}=\mathrm{test}$ at $5 \%$ significant level gave $[\mathrm{t}=5.00, p<0.01]$. There was a big difference in scores between the two groups on pattern recognition in favor of the experimental group, indicating the possible influence of previous background knowledge that these experimental groups were exposed to. This suggests, that during reading, contextual knowledge enhances the usage of text structure schemata, and by so doing, processing mental constraints do not exhaust the limitation of the working of the memory, and that load in the working memory, is largely reduced (Bruning, Schraw, \& Norby, 2011). Consequently, complex and loaded information, could be processed as a single element by the experimental groups, leaving enough space to be devoted to other mental processes, such as, selective attention (Schvaneveldt \& Mayer, 1973), comprehension monitoring etc. Thus, familiarity with background information most likely precipitated a reduced memory load, enabling them (experimental groups) to hold and manage varied segments of information simultaneously, and to apply better enhanced reading strategies (Just \& Carpenter, 1992). This process, referred to as schema automation, seemed to be the most plausible explanation, that might have assisted the experimental groups to overcome the Working Memory restrictions, to compensate for other cognitive processes to take place without too much load (Chi, Feltovich, \& Glaser, 1981; Afflerbach, 1986) therefore, outperforming the control group.

The findings strengthen what the cognitive load theory postulates, namely, that over-all, cognition is a blend of loads: extraneous load, intrinsic load, and germane. This totality needs to be accommodated within bounds of limited working memory capacity, because if it is over and above working memory's limited capacity, effective learning is undermined (van merrienboer \& Sweller, 2005).This means, that effective classroom teaching and learning, for example, is contingent upon the number of concurrent load that students can process at a time. Therefore, if teaching is related to what is known and already familiar to students, the chances of element interactivity, causing too many materials to be processed at the same time, and negatively affecting selective attention, would be minimized. This psychological process of element interactivity undermines efficient learning, due to inability to distinguish, between what is relevant, and what is irrelevant, especially in the case of novices as opposed to expert learners (Schnotz \& Kürschner, 2007). This theoretical postulate, seemed to have been corroborated in this study because, comparing the scores of all the experimental groups exposed to contextual background information, the following pattern could be observed: significant divergent performances were 
observed between the Form Three and the Form One experimental groups. On the recall questions, the form three group performed significantly higher than the form one group [MD $=2.58, p<0.01]$. On inference making questions, the form one group performed significantly lower, than the form three group [MD $=-2.23, p<0.01]$ and on the pattern recognition questions, the form three experimental group again performed significantly better, than the form one experimental group [MD $=2.28, p<0.01]$. This was interpreted to mean, that experts (older students in this case), as opposed to novice (younger students), were more able to manage interacting elements, needed to be processed simultaneously, better than younger students. This was a possible indication, that age and experience were also critical indicators of better mental load management.

\section{Conclusion}

This paper sought to find answers to three fundamental questions: a) Does contextual knowledge reduce constraints on working memory?; b) If contextual knowledge implicates working memory load, does this lead to differences in reading efficiency, between those with prior knowledge, and those without prior knowledge? and c) Does prior knowledge reduce working memory constraints during reading? In all four measures, results suggested appreciable differences in performance between the two groups. This consistent better performance of the experimental groups in all the measures was interpreted as the plausible influence of the previous knowledge of analogous texts. Readers' privy to information, used text schemata to manage and process text in parallel as one element, allowing working memory constraints to be circumvented, enabling readers with background knowledge to distinguish between relevant and what was irrelevant, through the process of schema automation. As a result of this, Working Memory restrictions were circumvented to compensate for enhanced reading in the experimental groups than the control group. In conclusion, the following four points are the highlights of this study: a) text comprehension appears to be critically connected to previous knowledge; b).previous knowledge predicts schema instantiation and automation; c) This process of schema automation reduces processing load; d) the reduction in mental load precipitates selective attention, enhancing comprehension. Implications for classroom practice are that: a) Reading challenges especially at the basic level of education, essentially, have intrinsic psychological antecedents; b) effective teaching and learning of reading needs to be designed to control mental load, especially for second language users; c) teaching and learning of reading comprehension becomes effective, when taught within the context of what is already familiar to students, since familiarity appears to be critically linked to the control and accommodation of mental load.

Declaration of Conflicting Interests - The author declares no potential conflicts of interest with respect to the research, authorship, and/or publication of this article. Respondents who participated in this study did so with parental permission.

Funding - This author received no financial support for the research, authorship, and/or publication of this article.

Acknowledgement: Thus author acknowledges with sincere thanks the teachers and the schools where this study was conducted.

\section{References}

Adams, B. C., Bell, L. C., \& Perfetti, C. A. (1995). A trading relationship between reading skill and domain knowledge in children's text comprehension. Discourse Processes, 20, 302-323. https://doi.org/10.1080/01638539509544943

Afflerbach, P. (1986). The influence of prior knowledge on expert reader. In J. Niles \& R. Lalik (Eds.). National reading conference yearbook. Solving problems in literacy: Learners, teachers, and researchers (Vol. 35, pp. 30-40). Rochester, NY: National Reading Conference.

Anderson, R. C. (1994). Role of the reader's schema in comprehension, learning, and memory. In R. B. Ruddell, 
M. R. Ruddell, \& H. Singer, (Eds.). Theoretical models and processes of reading (pp. 469-482). Newark, DE: International Reading Association.

Anderson, R. C., Pichert, J. W., \& Shirey, L. L. (1983). Effects of the reader's schema at different points in time. Journal of Educational Psychology, 75(2), 271-229. https://doi.org/10.1037/0022-0663.75.2.271

Anderson, R. C., Stevens, K. C., Shifrin, Z., \& Osborn, J. H. (1978). Instantiation of word meanings in children. Journal of Reading Behavior, 10, 149-157. https://doi.org/10.1080/10862967809547264

Anderson, R. C., Wang, Q., \& Gaffney, J. S. (2006). Comprehension research over the past three decades. In K.A. Dougherty Stahl, \& M. C. McKenna (Eds.). Reading research at work: Foundations of effective practice (pp. 275-283). New York: Guilford.

Anderson, R.C., \& Pearson, P. D. (1984). A schema-theoretic view of basic processes in reading. In P.D. Pearson (Ed.). Handbook of reading research (pp.255-291). New York: Longman.

Baddeley, A. D., \& Hitch, G. J. (1974). Working memory. In G. A. Bower (Ed.). Recent advances in learning and motivation (Vol. 8, pp. 47-89). New York: Academic Press. https://doi.org/10.1016/S0079-7421(08)60452-1

Bransford, J. D., \& Johnson, M. K. (1972). Contextual prerequisites for understanding: Some investigation of comprehension and recall. Journal of Verbal Learning and Verbal Behavior, 11, 717-726. https://doi.org/10.1016/S0022-5371(72)80006-9

Britton, B. K., Glynn, S. M., Meyer, B. J. F., \& Penland, M. J. (1982). Effects of text structure on use of cognitive capacity during reading. Journal of Educational Psychology, 74(1), 51-61. https://doi.org/10.1037/0022-0663.74.1.51

Bruning, R., Schraw, G., \& Norby, M. (2011). Cognitive psychology and instruction (5th ed.). Boston, MA: Pearson.

Cain, K., \& Oakhill, J. (2007). Children's comprehension problems in oral and written language: A cognitive perspective. New York: Guilford Press.

Cain, K., \& Oakhill, J. V. (1999). Inference making and its relation to comprehension failure. Reading \& Writing, 11, 489-503. https://doi.org/10.1023/A:1008084120205

Chi, M., Feltovich, P., \& Glaser, R. (1981). Categorization and representation of physics problems by experts and novices. Cognitive Science, 5, 121-152. https://doi.org/10.1207/s15516709cog0502_2

Daneman, M., \& Carpenter, P. A. (1980). Individual differences in working memory and reading. Journal of Verbal Learning \& Verbal Behavior, 19, 450-466. https://doi.org/10.1016/S0022-5371(80)90312-6

Daneman, M., \& Green, I. (1986). Individual differences in comprehending and producing words in context. Journal of Memory and language, 25, 1-18. https://doi.org/10.1016/0749-596X(86)90018-5

Detterman, D. (1993). The case for the prosecution: Transfer as an epiphenomenon. In D. Detterman, \& R. J. Sternberg (Eds.), Transfer on trial: Intelligence, cognition and instruction (pp. 1-22). NJ: Ablex.

Engle, R.W. (2001). What is working memory capacity? In H. L. Roediger \& J. S. Nairne (Eds.), The nature of remembering: Essays in honor of Robert G. Crowder (pp. 297-314). Washington, DC: American Psychological Association. https://doi.org/10.1037/10394-016

Ericsson, K. A., \& Kintsch, W. (1995) Long-term working memory. Psychological Review, 102, 211-245. https://doi.org/10.1037/0033-295X.102.2.211

Ewers, C. A., \& Brownson, S. M. (1999). Kindergartners' vocabulary acquisition as a function of active vs. passive storybook reading, prior vocabulary, and working memory. Reading Psychology, 20(1), 11-20. https://doi.org/10.1080/027027199278484

Freebody, P., \& Anderson, R. C. (1983). Effects of vocabulary difficulty, text cohesion, and schema availability on reading comprehension. Reading Research Quarterly, 18, 277-294. https://doi.org/10.2307/747389

Ghartey Ampiah, J. (2010). Quality basic education in Ghana: Prescription, praxis and problems. Paper presented at the Experience Sharing Seminar, January 17-19, 2010, Erata Hotel, Accra.

Glover, J. A., Dinnel, D. J., Halpain, D. R., Mckee, T. K., Corkhill, A. J., \& Wise, S. L. (1988). Effects of across-chapter signals on recall of text. Journal of Educational Psychology, 80, 3-15. https://doi.org/10.1037/0022-0663.80.1.3

Goerss, B., Beck, I., \& Mckeown, M. (1999). Increasing remedial students' ability to derive word meaning from 
Text familiarity predict schema automation to reduce Working Memory Capacity

context. Reading Psychology, 20(2), 151-175. https://doi.org/10.1080/027027199278457

Griffin, C., Malone, L., \& Kameenui, E. (1995). Effects of graphic organizer instruction on fifth-grade students. Journal of Educational Research, 89, 98-107. https://doi.org/10.1080/00220671.1995.9941200

Johnson-Laird P. (1983). Mental models. Cambridge, MA: Harvard University Press.

Just, M. A., \& Carpenter, P. A. (1992). Capacity theory of comprehension: Individual differences in working memory. Psychological Review, 99, 122-149. https://doi.org/10.1037/0033-295X.99.1.122

Kaakinen, J. K., Hyönä J., \& Keenan, J. M. (2003). How prior knowledge, WMC, and relevance of information affect eye fixations in expository text. Journal of Experimental Psychology: Learning, Memory, \& Cognition, 29, 447-457. https://doi.org/10.1037/0278-7393.29.3.447

Kintsch, W. (1988a). The use of knowledge in discourse processing: A construction-integration model. Psychological Review, 95, 163-182. https://doi.org/10.1037/0033-295X.95.2.163

Kintsch, W. (1998b). Comprehension: A paradigm for cognition. New York: Cambridge University Press.

Kuhn, M. R., \& Stahl, S. A. (1998). Teaching children to learn word meanings from context: A synthesis and some questions. Journal of Literacy Research, 30, 119-138. https://doi.org/10.1080/10862969809547983

Loman, N. L., \& Mayer, R. E. (1983). Signaling techniques that increase the understandability of expository prose. Journal of Educational Psychology, 75(3), 402-412. https://doi.org/10.1037/0022-0663.75.3.402

Lorch, R. F. Jr., \& Chen, A. H. (1986). Effects of number signals on reading and recall. Journal of Educational Psychology, 78, 263-270. https://doi.org/10.1037/0022-0663.78.4.263

Lorch, R. F. Jr., \& Lorch, E. P. (1985). Topic structure representation and text recall. Journal of Educational Psychology, 77, 137-148. https://doi.org/10.1037/0022-0663.77.2.137

Lorch, R. F. Jr., Lorch, E. P., \& Inman, W. E. (1993). Effects of signaling topic structure on text recall. Journal of Educational Psychology, 85(2), 281-290. https://doi.org/10.1037/0022-0663.85.2.281

Manset-Williamson, G., \& Nelson, J. M. (2005). Balanced, strategic reading instruction for upper-elementary and middle school students with reading disabilities: A comparative study of two approaches. Learning Disability Quarterly, 28, 59-74. https://doi.org/10.2307/4126973

Miller, G. A. (1956). The magical number seven, plus or minus two: Some limits on our capacity for processing information. Psychological Review, 63(2), 81-97. https://doi.org/10.1037/h0043158

Miller, L. M. S, \& Stine-Morrow, E. A. L. (1998). Aging and the effects of knowledge on on-line reading strategies. Journal of Gerontology: Psychological Sciences, 53, 223-233. https://doi.org/10.1093/geronb/53B.4.P223

Moravcsik, J. E., \& Kintsch, W. (1993). Writing quality, reading skill, and domain knowledge as factors in text comprehension. Canadian Journal of Psychology, 47, 360-374. https://doi.org/10.1037/h0078823

Nagy, W. E., Anderson, R. C., \& Herman, P. A. (1987). Learning words meanings from context during normal reading. American Educational Research Journal, 24(2), 237-270. https://doi.org/10.3102/00028312024002237

Nagy, W. E., Herman, P. A., \& Anderson, R. C. (1985). Learning words from context. Reading Research Quarterly, 20(2), 233-253. https://doi.org/10.2307/747758

Nation, K., \& Snowling, M. J. (1988). Semantic processing and the development of word recognition skills: Evidence from children with reading comprehension difficulties. Journal of memory and language, 39 , 85-101. https://doi.org/10.1006/jmla.1998.2564

Pearson, P. D., \& Johnson, D. D. (1978). Teaching reading comprehension. New York Holt, Ronehart \& Winston.

Pressley, M. (1998). Reading instruction that works: The case for balanced teaching. New York: Guilford.

Rawson, K. A., \& Kintsch, W. (2002). How does background information improve memory for text content? Memory \& Cognition, 30, 768-778. https://doi.org/10.3758/BF03196432

Reed, S. K. (1993). A scheme based theory of transfer. In D. Detterman \& R. J. Sternberg (Eds.). Transfer on trial: Intelligence, cognition and instruction (pp. 39-64). Norwood, NJ: Ablex.

Schnotz, W., \& Kürschner, C. (2007). A reconsideration of cognitive load theory. Educational Psychology Review, 19, 469-508. https://doi.org/10.1007/s10648-007-9053-4

Schvaneveldt, R. W., \& Meyer, D. E. (1973). Retrieval and comparison processes in semantic memory. In S. 
Kornblum (Ed.), Attention and performance IV (pp. 395-409). New York: Academic Press.

Schwanenflugel, P. J., \& Shoben, E. J. (1983). Differential context effects in the comprehension of abstract and concrete verbal materials. Journal of Experimental Psychology: Learning, Memory, and Cognition, 9(1), 82-102. https://doi.org/10.1037/0278-7393.9.1.82

Shapiro, A. M. (2004). How including prior knowledge as a subject variable may change outcomes of learning research. American Educational Research Journal, 41(1), 159-189. https://doi.org/10.3102/00028312041001159

Snow,C. (2002). Reading for understanding toward $R \&$ D programmes in reading comprehension. Santa Monica, Ca: Rand.

Stanovich, K. E. (1986). Mathew effects in reading: Some consequences of individual differences in the acquisition of literacy. Reading Research Quarterly, 21, 360-407. https://doi.org/10.1598/RRQ.21.4.1

Stull, A., \& Mayer, R. E. (2007). Learning by doing verses learning by viewing: Three experimental comparisons of learner-generated verses author-generated graphic organizer, Journal of Educational Psychology, 99(4), 808-820. https://doi.org/10.1037/0022-0663.99.4.808

Summers, W. V., Horton, D. L., \& Diehl, V. A. (1985). Contextual knowledge during encoding influences sentence recognition. Journal of Experimental Psychology: Learning, Memory, \& Cognition, 11, 771-779. https://doi.org/10.1037/0278-7393.11.1-4.771

Sweller, J., van Merriënboer, J. J. G., \& Paas, J. G. W. C. (1998). Cognitive architecture and instructional design. Educational Psychology Review, 10, 251-295. https://doi.org/10.1023/A:1022193728205

Van Dijk, T. A., \& Kintsch, W. (1983). Strategies of discourse comprehension. New York: Academic.

Van Merriënboer, J. J. G., \& Sweller, J. (2005). Cognitive load theory and complex learning: Recent development and future directions. Educational Psychology Review, 17, 147-177. https://doi.org/10.1007/s10648-005-3951-0

Vicente, K. J., \& Wang, J. H. (1998). An ecological theory of expertise effects in memory recall. Psychological Review, 105, 33-57. https://doi.org/10.1037/0033-295X.105.1.33

Vipond, D. (1980). Micro- and macroprocesses in text comprehension. Journal of Verbal Learning \& Verbal Behavior, 19(3), 276-296. https://doi.org/10.1016/S0022-5371(80)90230-3

Wiley, J., \& Rayner, K. (2000). Effects of titles on the processing of text and lexically ambiguous words: Evidence from eye movements. Memory \& Cognition, 28, 1011-1021. https://doi.org/10.3758/BF03209349 